\title{
Effect of Poh-wi (Pittosporum ramosii Merr.) Bark and Leaves and Bakuwog (Sandoricum vidallii Merr.) Bark in the Control of Golden Apple Snails
}

\author{
Gumayon, Ruby Ann C. and Bulong, Marissa P*. \\ *Ifugao State University, Nayon, Lamut, Ifugao, Philippines
}

\begin{abstract}
Molluscicidal action of plants is significant in managing pests like golden apple snails (GAS), thus studies explored these as organic pesticides. A study tested effect of Poh-wi (Pittosporum ramosii Merr.) bark and leaves and Bakuwog (Sandoricum vidallii Merr.) bark in controlling GAS. Experiment was done in four blocks measuring $1 \mathrm{~m} \times 1 \mathrm{~m}$, each containing 30 pieces of GAS and in a $5 \mathrm{~m} \times 5 \mathrm{~m}$ rice field infested with GAS. Treatments were: T1 - Bakuwog bark; T2 - Poh - wi bark; T3 - Poh - wi leaves; and T4 - Poh - wi bark and leaves. A high mortality rate was noted in T4. Fastest molluscicidal action was observed after 12 hours of applying Treatments 2 and 4 that caused GAS to die. In view of the molluscicidal potential of Poh - wi bark and Poh - wi bark and leaves, analyzing for molluscicidal property identification and exploiting them further as organic molluscicides for sustainable GAS management in organic rice production can be done.
\end{abstract}

Keywords: effect, golden apple snail, molluscicide, organic pesticide

\section{Introduction}

\subsection{Rationale}

The Golden apple snail (GAS) has been ranked as a pest of national importance. It is an aquatic gastropod from South America that was introduced by the Philippine government as a means of livelihood program and as a cheap source of protein for low income Filipinos. However, after years of its introduction and improper rearing, the GAS found their way to every waterways and rice field which caused potential damage in rice farming resulting to yearly decline in rice yield.

Banaue Rice Terraces, a UNESCO declared world heritage site is not exempted from the infestation of this rice pest. In fact, the GAS is considered as the major rice pest in this locality. The farmer folks also believed and blamed GAS for the drastic extinction of the edible Native Apple Snail (Pila conica) or "batikul", loach or "yuyu" (Migornus anguillicaudatus) and the soft shelled "ginga" in the rice terraces.

The Banaue rice farmers practiced several control methods like manual hand picking, baiting and application of some indigenous plants as an alternative molluscicide. Only a few use commercial mulluscicide since some of the rice farmers especially those in the barrios consume GAS as viand.

Therefore, it is best to educate and inform the farmers in Banaue on the different uses of GAS and introduce indigenous plant materials available to control or eradicate this pest without harming the other forms of life in the rice field ecosystem. Taguiling and Buyuccan (2009) conducted an experiment to determine the effect of santol fruit in controlling GAS and to compare its effect with malasantol. Ngaloy and Andrada (2005) verified the effectiveness of dried pulverized malasantol fruit in controlling GAS under laboratory condition.

\subsection{Objectives}

Generally, the study was conducted to test the effect of Poh-wi and Bakuwog in controlling golden apple snail under field condition.

Specifically, the study aimed to:

- Determine the effect of Poh-wi bark and leaves and Bakuwog bark in controlling golden apple snail; and 
- Determine the molluscicidal action of Poh-wi bark and leaves and Bakuwog bark in controlling golden apple snail.

\section{Methodology}

The study was laid out in a Randomized Complete Block Design (RCBD) with three replications. All the plant parts and materials needed were prepared. The first experiment was done in four blocks with an area of $1 \mathrm{~m}$ x $1 \mathrm{~m}$, each block containing 30 pieces of golden apple snails of different sizes. The second experiment used a wider area of $5 \mathrm{~m}$ x $5 \mathrm{~m}$ rice field infested with GAS. The treatments used are: T1- Bakuwog bark; T2-Poh - wi bark; T3 - Poh - wi leaves; and T4 - Poh - wi bark and leaves.

All plant parts were gathered from the locality. For the $1 \mathrm{~m} \times 1 \mathrm{~m}$ area, two kilograms each of the bark taken from a small portion of the whole was cut into pieces. Two kilograms each of the leaves was chopped. For the combination of leaves and bark, one kilogram of the leaves which was chopped was mixed with one kilogram of the bark cut into pieces. The quantity of two kilograms was based on the practice of the Asipulo farmers of using two kilograms of ripe Bakuwog fruits to eradicate GAS as cited by Ngaloy, et al (2002). For the 5m x 5m area, ten kilograms each of the plant materials was used. All treatments were directly applied in the blocks were no indigenous edible snails were present. In the $1 \mathrm{~m} \times 1 \mathrm{~m}$ area, the treatments were applied at a depth of one foot. In the $5 \mathrm{~m} \times 5 \mathrm{~m}$ area, the treatments were applied at a depth of $5 \mathrm{~cm}$. Mortality rates were observed within 12 to 24 hours.

\section{Results and Discussion}

\subsection{Effect of Poh - wi bark and leaves and Bakuwog bark in controlling golden apple snail}

The number of golden apple snails that died in an area of $1 \mathrm{~m} \times 1 \mathrm{~m}$ and a $5 \mathrm{~m} \times 5 \mathrm{~m}$ area, respectively is presented in Tables I and II. Based on the result of the study, F - test revealed significant differences whereby T4 is significantly different from the other treatments. Treatment 4 (Poh - wi bark and leaves) had the highest mortality rate. Result confirms the study of Taguiling and Buyuccan (2009) that the higher the concentration of milled santol fruit and santol fruit extracts, the higher the mortality observed on GAS.

TABLE I: Golden Apple Snail Mortality (In Pieces)

\begin{tabular}{|c|c|c|c|c|}
\hline \multicolumn{5}{|c|}{ Area $=1 \mathrm{~m} \times 1 \mathrm{~m}$} \\
\hline Treat-ment & Rep 1 & Rep 2 & $\operatorname{Rep} 3$ & Average \\
\hline T1 & 44 & 51 & 43 & $46^{b}$ \\
\hline T2 & 53 & 56 & 56 & $55^{\mathrm{c}}$ \\
\hline T3 & 40 & 41 & 39 & $40^{\mathrm{a}}$ \\
\hline T4 & 56 & 60 & 58 & $58^{\mathrm{d}}$ \\
\hline
\end{tabular}

TABLE II: Golden Apple Snail Mortality (in pieces) Area $=5 \mathrm{~m} \times 5 \mathrm{~m}$

\begin{tabular}{|l|c|c|c|c|}
\hline Treat-ment & Rep 1 & Rep 2 & Rep 3 & Average \\
\hline T1 & 27 & 28 & 29 & $28^{\mathrm{a}}$ \\
\hline T2 & 42 & 38 & 40 & $40^{\mathrm{c}}$ \\
\hline T3 & 30 & 32 & 36 & $33^{\mathrm{b}}$ \\
\hline T4 & 68 & 64 & 66 & $66^{\mathrm{d}}$ \\
\hline \multicolumn{5}{|c|}{ p-value $=0.000$} \\
p-value $=0.42$
\end{tabular}




\subsection{Molluscicidal action of Poh-wi bark and leaves and Bakuwog bark in controlling GAS}

Tables III and IV show the duration when the molluscicidal action of the different treatments caused the GAS to die. $\mathrm{F}$ - test showed significant differences whereby T2 and T4 are significantly different from the other treatments. The fastest molluscicidal action was observed after 12 hours of applying Treatments 2 and 4 that caused GAS to stay motionless and eventually die in both areas. This contradicts the findings of Taguiling and Buyuccan (2009) that GAS were effectively controlled after 24 hours. These results imply that the wider the area, the larger the volume of the treatments be applied in order to obtain a high mortality rate at a faster time.

TABLE III: Molluscicidal Action (In Hours)

Area $=1 \mathrm{~m} \times 1 \mathrm{~m}$

\begin{tabular}{|l|c|c|c|c|}
\hline Treat-ment & Rep 1 & Rep 2 & Rep 3 & Average \\
\hline T1 & $\mathbf{2 6}$ & $\mathbf{2 2}$ & $\mathbf{2 4}$ & $\mathbf{2 4}^{\mathbf{b}}$ \\
\hline T2 & 12 & 12 & 12 & $12^{\mathrm{a}}$ \\
\hline T3 & 24 & 26 & 22 & $24^{\mathrm{b}}$ \\
\hline T4 & 12 & 12 & 12 & $12^{\mathrm{a}}$ \\
\multicolumn{2}{|c|}{ F-treatment } & $=52.364$ & \multicolumn{3}{c|}{ p-value $=0.000$} \\
F-block & $=0.273$ & & p-value $=0.770$
\end{tabular}

TABLE IV: Molluscicidal Action (In Hours) Area $=5 \mathrm{~m} \times 5 \mathrm{~m}$

\begin{tabular}{|l|c|c|c|c|}
\hline Treat-ment & Rep 1 & Rep 2 & Rep 3 & Average \\
\hline T1 & 28 & 22 & 24 & $24^{\mathrm{b}}$ \\
\hline T2 & 12 & 12 & 12 & $12^{\mathrm{a}}$ \\
\hline T3 & 22 & 26 & 24 & $24^{\mathrm{b}}$ \\
\hline T4 & 12 & 12 & 12 & $12^{\mathrm{a}}$ \\
\hline \multicolumn{4}{|c|}{ F-treatment } & $=32.070$ \\
F-block & $=0.018$ & \multicolumn{3}{c|}{ p-value $=0.000$} \\
p-value $=0.983$
\end{tabular}

\section{Conclusion}

- Fresh bark of Poh - wi and Poh - wi fresh bark and leaves are effective in controlling golden apple snail. The smaller the area treated with Treatments 2 and 4, the higher the mortality.

- The molluscicidal action of fresh bark of Poh - wi and a combination of fresh leaves and bark of Poh wi killed golden apple snail after 12 hours of exposure to the said Treatment.

\section{Recommendations}

- Treatments 2 and 4 should be subjected to laboratory analysis to determine their molluscicidal property. Further studies on increasing the volume of Treatments 2 and 4 should be conducted to verify the results.

- Applying Treatments 2 and 4 in rice paddies where there are standing rice crops should be done to determine whether the Treatment is detrimental to the rice crops' growth and yield or not.

- Fresh bark of Poh - wi and Poh - wi bark and leaves can be exploited further as organic molluscicides for sustainable GAS management in organic rice production.

\section{References}

[1] I.T. Ngaloy and M.G. Andrada, "Effect of Pulvurized Dried Bakuwog Fruit on Golden Apple Snail," Ecosystems Research Digest (15) 2. 2005.

[2] I.T. Ngaloy, M.G. Andrada and D.A. Estigoy, "The indigenous Bakuwog tree; Eradicator of the exotic Golden Snail," Canopy International, pp. 3, 2002.

[3] N.K. Taguiling and M.G. Buyuccan, "Effect of Santol Fruit on Golden apple Snail," The Upland Farm Journal (18) 1, pp. 88, 2009. 